\title{
The Callander laryngoscope blade modification is associated with a decreased risk of dental contact
}

\author{
[La modification Callander de la lame du laryngoscope est associée à un moindre \\ risque de contact avec les dents]
}

Jaemin Lee MD, ${ }^{*}$ Jong H. Choi MD, ${ }^{*}$ Yoon K. Lee $\mathrm{MD},{ }^{*}$ Eun S. Kim MD, ${ }^{*}$ Ou K. Kwon MD, Randolph H. Hastings MD PhD†

Purpose: Dental damage may occur with laryngoscopy. The purpose of this study was twofold: to determine whether preoperative examination could predict the risk of contacting the teeth with the laryngoscope and to evaluate the effectiveness of a modified Macintosh blade on reducing dental contact.

Methods: Four hundred and eighty-three patients scheduled for elective surgery requiring general anesthesia with endotracheal tube placement were studied prospectively. Features that might predict difficult intubation were assessed preoperatively. Laryngoscopy was performed twice on each patient, once with a regular Macintosh 3 blade and once with a blade in which the flange was partially removed (Callander modification). The distance between the flange of the blade and the upper incisors at glottic exposure was measured. We calculated correlations between individual airway characteristics and the chance of hitting the upper teeth with the regular Macintosh 3 blade and compared the frequencies of contacting the teeth between the two blades.

Results: The chance of hitting the upper teeth when using the regular Macintosh 3 blade increased significantly with non-parametric scores for Mallampati classification, mandibular subluxation, head and neck movement, interincisor gap, and condition of the upper teeth. $(P<0.01)$ The frequency of direct contact varied significantly between the two blades: $20.3 \%$ vs $4.1 \%$ for Macintosh 3 and modified blades, respectively $(P<0.05)$. Laryngeal views were improved with the modified blade.

Conclusion: Airway characteristics correlate with the risk of hitting the upper teeth during laryngoscopy. The modified Macintosh blade reduces the risk of contacting the teeth.
Objectif : La laryngoscopie peut provoquer des lésions aux dents. Notre double objectif était : de déterminer si l'examen préopératoire peut permettre de prédire le risque de toucher les dents avec le laryngoscope et d'évaluer l'efficacité d'une lame Macintosh modifiée sur la réduction de contact avec les dents.

Méthode : Des patients (483) devant subir une intervention chirurgicale réglée nécessitant une anesthésie générale avec la mise en place d'un tube endotrachéal ont participé à notre étude prospective. Nous avons fait l'évaluation préopératoire des caractéristiques permettant de prédire une intubation difficile. La laryngoscopie a été réalisée deux fois sur chaque patient, avec une lame Macintosh 3 ordinaire et avec une lame dont le connecteur à bride avait été partiellement enlevé (modification Callander). La distance entre le manche de la lame et les incisives supérieures a été mesurée à l'exposition de la glotte. Nous avons calculé les corrélations entre les caractéristiques individuelles des voies aériennes et le risque de toucher les dents supérieures avec la lame Macintosh 3 ordinaire, et comparé les fréquences de contact avec les dents pour les deux lames.

Résultats : Le risque de toucher les dents supérieures avec la lame Macintosh 3 ordinaire augmente significativement avec les scores nonparamétriques de la classification de Mallampati, la subluxation mandibulaire, le mouvement de la tête et du cou, l'espace inter-incisive et l'état de la dentition supérieure $(P<0,01)$. La fréquence de contact direct varie significativement d'une lame à l'autre : 20,3\% vs 4 I \% respectivement pour la lame Macintosh 3 et la lame modifiée $(P<0,05)$. Les visualisations du larynx sont meilleures avec la lame modifiée.

Conclusion : Il existe une corrélation entre les caractéristiques des voies aériennes et le risque de toucher les dents supérieures pendant la laryngoscopie. La lame Macintosh modifiée réduit ce risque.

From the Department of Anesthesiology, School of Medicine, The Catholic University of Korea, ${ }^{*}$ Seoul, Korea; and the Anesthesiology Service, VA San Diego Healthcare System, $†$ San Diego, California, USA.

Address correspondence to: Dr. Eun S. Kim, Department of Anesthesiology, School of Medicine, The Catholic University of Korea, Kangnam Saint Mary's Hospital, 505 Banpo-Dong, Seocho-Gu, Seoul 137-040, Korea. Phone: 82-2-590-1545; Fax: 82-2-537-1951; E-mail: euns1503@catholic.ac.kr

The authors wish to acknowledge the financial support of the Catholic Medical Center Research Foundation made in the program year of 2003.

Accepted for publication June 2, 2003.

Revision accepted November 11, 2003. 


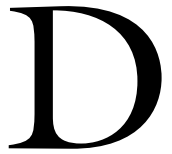

ENTAL trauma is the most common complication of general anesthesia and it is the largest single reason for successful malpractice claims against anesthesiologists. ${ }^{1,2}$ It is more likely in cases with difficult tracheal intubation, ${ }^{2}$ possibly because anesthesiologists may use the upper teeth as a fulcrum when they cannot obtain a satisfactory view of the glottis. Thus, preoperative factors that predict difficult intubation might also predict the risk of dental trauma. The goals of this study were to test this hypothesis and to evaluate whether a modification of the laryngoscope blade ${ }^{3}$ could reduce the frequency of hitting the teeth.

\section{Methods}

The 483 consenting patients in this Institutional Review Board approved study were ASA I or II, aged 16 or older, undergoing elective surgery requiring general anesthesia with endotracheal tube placement. Patients were excluded for inability to cooperate, cervical spine fracture or instability, history of gastroesophageal reflux, traumatic facial abnormalities and absence of teeth.

Airway factors ${ }^{4,5}$ listed in Table I were assessed preoperatively. For Mallampati classification, the seated patient protruded the tongue maximally. ${ }^{4}$ For the measurement of head and neck movement, the patient extended the head and neck fully while a pencil was stood vertically on the forehead. The orientation of the pencil was adjusted so that it was parallel to a distant vertical frame of the window. ${ }^{5}$ Then, while the pencil was held firmly in position, the head and neck were fully flexed and the pencil was sighted against the horizontal frame of the window to judge if it had moved through $90^{\circ}$. Age, sex and height were also recorded.

After induction of anesthesia and muscle paralysis, laryngoscopy was performed twice in random order by a faculty anesthesiologist or senior resident, once using a regular Macintosh 3 blade and once using a Macintosh 3 blade that had been modified by reducing the height of the flange ${ }^{3}$ (Figure). Laryngeal manipulation was not performed. An assistant measured the distance from the tip of the maxillary central incisor to the horizontal flange of each blade with a ruler when the glottis was maximally exposed. The laryngoscopist assessed the glottic view with the scale of Cormack and Lehane. ${ }^{6}$ Difficult intubation was defined as any one of the followings: grade IV laryngeal view; change in operator or technique; more than three attempts at laryngoscopy. ${ }^{7}$

Data were compared among groups by Wilcoxon's signed test, Fisher's exact test or Chi square, where appropriate. Correlations of variances were examined

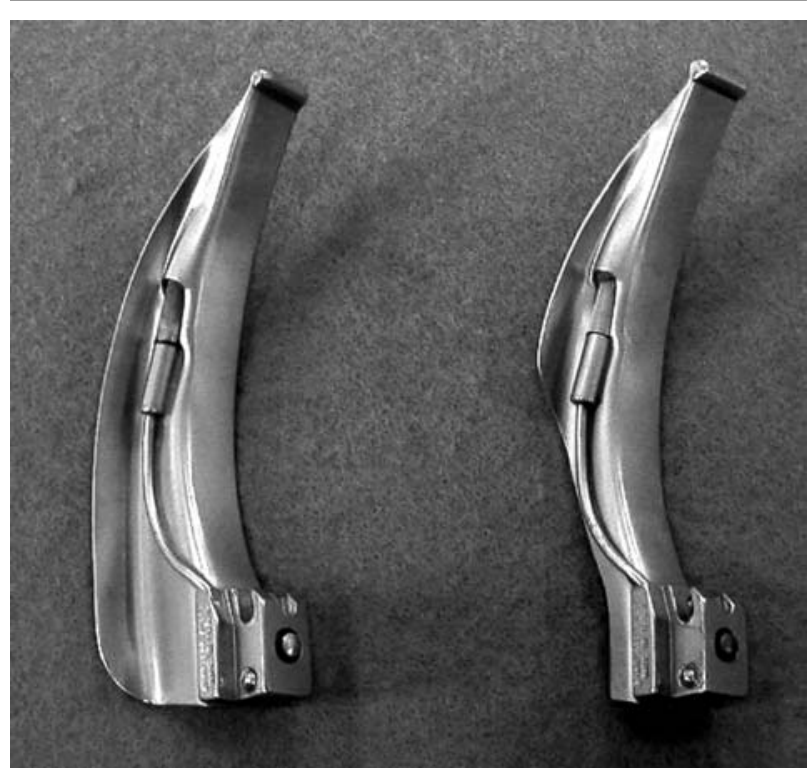

FIGURE The modified Macintosh blade (right side). The modification consists of a reduction in the height of the flange at the hilt of the blade but with no alteration in the position of the light source, as described by Callander $e t a l$. Left is the regular Macintosh blade.

by Spearman's correlation co-efficient. Results were considered significant if $P<0.05$.

\section{Results}

The mean age of patients was $44.9 \pm 13.0 \mathrm{yr}$, the mean height $161.7 \pm 7.8 \mathrm{~cm}$, and the mean body weight 60.1 $\pm 10.6 \mathrm{~kg}$. There were 141 males and 342 females.

No patient experienced dental injury. The frequency of tooth contact with the regular blade significantly increased with increases in the scores for Mallampati classification, mandibular subluxation, head and neck movement, interincisor gap and upper teeth condition (Table II). The blade-tooth distance was inversely related to the individual scores for the same variables $(P<0.01$ for all $)$. The frequency of blade-tooth contact was over $90 \%$ for some combinations of abnormalities: Mallampati 3 or more with buckteeth; inability to protrude the mandible plus head and neck movement $<90^{\circ}$; head and neck movement $<90^{\circ}$ with either buckteeth or interincisor gap $<5 \mathrm{~cm}$; and interincisor gap $<5 \mathrm{~cm}$ with buckteeth. Laryngoscopic view correlated inversely with bladetooth distance $(\mathrm{r}=-0.562 ; P<0.01)$.

Blade-tooth distances were $2(4) \mathrm{mm}$ and $7(8) \mathrm{mm}$ [median (interquartile gap)], respectively for the regular and modified blades. Dental contact occurred in 
TABLE I Preoperative assessment of airway characteristics

\begin{tabular}{lll}
\hline Airway characteristics & Score & Assessment \\
\hline Body weight & 1 & $<80 \mathrm{~kg}$ \\
& 2 & $\geq 80 \mathrm{~kg}$ \\
Mallampati classification & 1 & faucial pillars, soft palate and uvula are visible \\
& 2 & uvula is masked by the base of the tongue \\
& 3 & only the soft palate is visible \\
Mandibular subluxation & 4 & soft palate not visible \\
& 1 & $>0 \mathrm{~cm}$ \\
Head and neck movement & 2 & zero \\
& 3 & $<0 \mathrm{~cm}$ \\
Interincisor gap & 1 & 890 \\
Thyromental distance & 2 & $<80^{\circ}-90^{\circ}$ \\
Condition of upper teeth & 3 & $\geq 5 \mathrm{~cm}$ \\
& 1 & $<5 \mathrm{~cm}$ \\
& 2 & $\geq 7 \mathrm{~cm}$ \\
& 1 & $<7 \mathrm{~cm}$ \\
& 2 & normal \\
& 1 & buckteeth \\
\hline
\end{tabular}

TABLE II Frequencies of direct contact in individual airway characteristics

\begin{tabular}{|c|c|c|c|}
\hline Airway characteristics & Score & Frequency of direct & \\
\hline Body weight & 1 & $21.10 \%(96 / 455)$ & \\
\hline & 2 & $25.00 \%(7 / 28)$ & $P=0.232$ \\
\hline Mallampati classification & 1 & $11.93 \%(26 / 218)$ & \\
\hline & 2 & $25.40 \%(48 / 189)$ & \\
\hline & 3 & $31.43 \%(22 / 70)$ & \\
\hline & 4 & $33.33 \%(2 / 6)$ & $P<0.01$ \\
\hline Mandibular subluxation & 1 & $14.39 \%(62 / 431)$ & \\
\hline & 2 & $66.67 \%(24 / 36)$ & \\
\hline & 3 & $75.00 \%(12 / 16)$ & $P<0.01$ \\
\hline Head and neck movement & 1 & $17.28 \%(80 / 463)$ & \\
\hline & 2 & $90.00 \%(18 / 20)$ & $P<0.01$ \\
\hline Interincisor gap & 1 & $6.22 \%(12 / 193)$ & \\
\hline & 2 & $29.66 \%(86 / 290)$ & $P<0.01$ \\
\hline Thyromental distance & 1 & $21.46 \%(56 / 261)$ & \\
\hline & 2 & $18.92 \%(42 / 222)$ & $P=0.490$ \\
\hline Condition of upper teeth & 1 & $16.34 \%(74 / 453)$ & \\
\hline & 2 & $80.00 \%(24 / 30)$ & $P<0.01$ \\
\hline
\end{tabular}

The number of cases are given in parentheses. The frequencies of direct contact significantly increased with increases in the scores for Mallampati classification, mandibular subluxation, head and neck movement, interincisor gap, and condition of upper teeth.

$20.3 \%$ of patients $(98 / 483)$ with the regular blade $v$ s $4.1 \%(20 / 483)$ for the modified blade $(P<0.05)$. Laryngoscopic views were significantly better with the modified blade compared to the regular blade (Table III). Difficult intubation occurred in four patients with the regular blade, marked by grade IV views (not even epiglottis visible). In each case, the view improved to grade III with the modified blade.

\section{Discussion}

We have demonstrated a relationship between airway measurements and upper teeth contact during laryngoscopy. The same measurements also predict difficult laryngoscopy and intubation..$^{4,5}$ This is consistent with observations that difficult intubation predicts dental trauma. ${ }^{2}$ Thus, the measurements might be used to predict patients at increased risk of dental trauma, assuming that tooth contact and injury frequencies are related. However, we have no direct data concerning 
TABLE III Comparison of laryngoscopic view between two blades

\begin{tabular}{llll}
\hline Regular Macintosh blade & \multicolumn{2}{l}{ Modified Macintosh blade } \\
\hline Grade 1 & $41.6 \%(201 / 483)$ & Grade 1 & $74.7 \%(361 / 483)$ \\
Grade 2 & $41.8 \%(202 / 483)$ & Grade 2 & $23.2 \%(112 / 483)$ \\
Grade 3 & $15.7 \%(76 / 483)$ & Grade 3 & $2.1 \%(10 / 483)$ \\
Grade 4 & $0.8 \%(4 / 483)$ & Grade 4 & $0 \%(0 / 483) \quad P<0.01$ \\
\hline
\end{tabular}

The number of cases are given in parentheses. The modified Macintosh blade provided a greater field of view than the regular Macintosh blade.

the relationship between airway factors and the incidence of dental trauma. Other factors, such as the amount of force applied to the incisors, may be important for the risk of dental injury.

Using a modified low-height flange on a Macintosh blade reduced the frequency of direct contact between the blade and the upper teeth by over $80 \%$ compared to a regular blade. Thus, the modified blade might reduce the incidence of dental injury, if our assumption of an inverse relationship with blade-tooth distance is true. Other blade modifications, tooth protectors, or non-laryngoscopic methods to secure the airway can also be employed to avoid dental trauma. Angulated blades, such as the McCoy blade and the Belscope, have been reported to provide greater tooth-blade distances and better views than regular curved or straight blades. ${ }^{8.9}$ Distances for the Belscope, which lacks a horizontal flange, were $10 \mathrm{~mm}$ vs 1 to $3 \mathrm{~mm}$ for standard blades, ${ }^{9}$ similar to our results. Removing the flange may also reduce force during laryngoscopy, a property that might also reduce the risk of dental trauma. ${ }^{10}$

The flange on standard blades helps control the tongue during laryngoscopy and may serve other purposes. Thus removing the flange could make laryngoscopy or intubation more difficult. The modified blade produced no grade IV view compared to four grade IV views with the regular blade, suggesting that the risk of failed intubation is not greater with a flangeless blade and may even be less. The overall incidence of grade III or IV views was high compared to most reports, probably because we did not allow laryngeal manipulation, a maneuver that improves visualization. ${ }^{4}$

In summary, several routine airway measurements predict the risk of contacting teeth with the laryngoscope blade. The modified Macintosh blade with a low profile flange reduces the chance of hitting the upper teeth compared to the regular blade. It may reduce the likelihood of upper dental injury during laryngoscopy.

\section{References}

1 Owen H, Waddell-Smith I. Dental trauma associated with anaesthesia. Anaesth Intensive Care 2000; 28: $133-45$.

2 Warner ME, Benenfeld SM, Warner MA, Schroeder DR, Maxson PM. Perianesthetic dental injuries. Frequency, outcomes, and risk factors. Anesthesiology 1999; 90: 1302-5.

3 Callander CC, Thomas J. Modification of Macintosh laryngoscope for difficult intubation (Letter). Anaesthesia 1987; 42: 671-2.

4 Benumof JL. Management of the difficult adult airway. With special emphasis on awake tracheal intubation. Anesthesiology 1991; 75: 1087-110.

5 Wilson ME, Spiegelhalter D, Robertson JA, Lesser P. Predicting difficult intubation. Br J Anaesth 1988; 61: 211-6.

6 Cormack RS, Lehane J. Difficult tracheal intubation in obstetrics. Anaesthesia 1984; 39: 1105-11.

7 Benumof JL. The unanticipated difficult airway (Letter). Can J Anesth 1999; 46: 510-1.

8 Watanabe S, Suga A, Asakura N, et al. Determination of the distance between the laryngoscope blade and the upper incisors during direct laryngoscopy: comparisons of a curved, an angulated straight, and two straight blades. Anesth Analg 1994; 79: 638-41.

9 Bito H, Nishiyama T, Higarhizawa T, Sakai T, Konishi $A$. Determination of the distance between the upper incisors and the laryngoscope blade during laryngoscopy: comparisons of the McCoy, the Macintosh, the Miller, and the Belscope blades (Japanese). Masui 1998; 47: 1257-61.

10 Bucx MJ, Snijders CJ, van der Vegt MH, Holstein JD, Stijnen T. Reshaping the Macintosh blade using biomechanical modelling. A prospective comparative study in patients. Anaesthesia 1997; 52: 662-7. 